\title{
1 Solid-State NMR Investigations of the MHC II Transmembrane 2 Domains: Topological Equilibria and Lipid Interactions
}

\author{
Christopher Aisenbrey ${ }^{1} \cdot$ Evgeniy S. Salnikov $^{1} \cdot$ Burkhard Bechinger $^{1,2}$ (D)
}

Received: 18 February 2019 / Accepted: 25 May 2019

(c) Springer Science+Business Media, LLC, part of Springer Nature 2019

\begin{abstract}
The major histocompatibility complex class II (MHC II) membrane proteins are key players in the adaptive immune response. An aberrant function of these molecules is associated with a large number of autoimmune diseases such as diabetes type I and chronic inflammatory diseases. The MHC class II is assembled from DQ alpha 1 and DQ beta 1 which come together as a heterodimer through GXXXG-mediated protein-protein interactions and a highly specific protein-sphingomyelin-C18 interaction motif located on DQA1. This association can have important consequences in regulating the function of these membrane proteins. Here, we investigated the structure and topology of the DQA1 and DQB1 transmembrane helical domains by CD-, oriented ${ }^{2} \mathrm{H}$ and ${ }^{15} \mathrm{~N}$ solid-state NMR spectroscopies. The spectra at peptide-to-lipid ratios of 0.5 to $2 \mathrm{~mol} \%$ are indicative of a topological equilibrium involving a helix crossing the membrane with a tilt angle of about $20^{\circ}$ and another transmembrane topology with around $30^{\circ}$ tilt. The latter is probably representing a dimer. Furthermore, at the lowest peptide-to-lipid ratio, a third polypeptide population becomes obvious. Interestingly, the DQB1 and to a lesser extent the DQA1 transmembrane helical domains exhibit a strong fatty acyl chain disordering effect on the inner segments of the ${ }^{2} \mathrm{H}$-labelled palmitoyl chain of POPC bilayers. This phosphatidylcholine disordering requires the presence of sphingomyelin-C18 suggesting that the ensemble of transmembrane polypeptide and sphingolipid exerts positive curvature strain.
\end{abstract}

Keywords Transmembrane dimer · Highly specific protein-lipid interaction - Sphingomyelin - Supported lipid bilayer .

Solid-state NMR · Helix topology · DQA1 of MHC II · Order parameter

Electronic supplementary material The online version of this article (https://doi.org/10.1007/s00232-019-00071-8) contains supplementary material, which is available to authorized users.

Christopher Aisenbrey and Evgeniy S. Salnikov have equally contributed to this work.

Burkhard Bechinger

bechinge@unistra.fr

Christopher Aisenbrey

aisenbrey@unistra.fr

Evgeniy S. Salnikov

genek@mail.ru

1 Institut de Chimie, Université de Strasbourg/CNRS, UMR7177, 4, Rue Blaise Pascal, 67070 Strasbourg, France

2 Faculté de Chimie, Institut le Bel, 4, Rue Blaise Pascal, 67070 Strasbourg, France

\begin{tabular}{|c|c|}
\hline \multicolumn{2}{|c|}{ Abbreviations } \\
\hline DHPC & $\begin{array}{l}\text { 1,2-Dihexanoyl-sn-glycero-3-phosphocho- } \\
\text { line }\end{array}$ \\
\hline DMPC & $\begin{array}{l}\text { 1,2-Dimyristoyl-sn-glycero-3-phosphocho- } \\
\text { line }\end{array}$ \\
\hline DQA1-TMD & $\begin{array}{l}\text { KK TETVV CALGL SVGLV GIVVG } \\
\text { TVFII RGLRS KK }\end{array}$ \\
\hline DQB1-TMD & $\begin{array}{l}\text { KK QSKML SGIGG FVLGL IFLGL } \\
\text { GLIIH HRSQK K }\end{array}$ \\
\hline LWHH & Line width at half height \\
\hline $\mathrm{MHC}$ & Major histocompatibility complex \\
\hline NMR & Nuclear magnetic resonance \\
\hline POPC & $\begin{array}{l}\text { 1-Palmitoyl-2-oleoyl-sn-glycero-3-phos- } \\
\text { phocholine }\end{array}$ \\
\hline SM & Sphingomyelin \\
\hline SM-C18 & $\begin{array}{l}N \text {-octadecanoyl-D-erythro-sphingosylphos- } \\
\text { phorylcholine }\end{array}$ \\
\hline TMD & Transmembrane domain \\
\hline
\end{tabular}




\section{Introduction}

A. 2 There is increasing evidence that the function of membrane proteins critically depends on their direct lipid environment and that membrane protein activity can be modulated by binding to specific lipids. Whereas bulk lipids exchange fast with others in close proximity, the residence time is extended by specific interactions of the protein with polar head groups of lipids, and/or by hydrophobic matching to their hydrocarbon chains. Individual lipid molecules have been detected in crystallographic structures at the periphery or the oligomerisation interface of membrane proteins (Palsdottir et al. 2003). Notably, enzymatic or channel activities of a number of proteins that are dependent on the bilayer lipid composition have been described (for reviews see Hille et al. 2015; Stangl and Schneider 2015).

A few years ago a highly selective lipid-binding motif was identified for the p24 family of proteins which are associated with coat protein I transport vesicles (Contreras et al. 2012). The latter assures the retrograde transport of the early secretory pathway by shuttling from the early Golgi back to the endoplasmatic reticulum (Strating and Martens 2009). Within the carboxy-terminus of the transmembrane region of $\mathrm{p} 24$, the amino acid motif VXXTLXXIY recognizes both the head group and the exact length of the fatty acyl chain (18 C atoms) of $N$-stearoylsphingomyelin (SM-C18) (Contreras et al. 2012).

Starting from this sequence, a bioinformatics analysis identified a number of protein candidates with signatures homologous to this highly specific sphingolipid-recognition motif (Bjorkholm et al. 2014). Most of these proteins localize to the plasma membrane and to organelles of the secretory pathway and include the alpha- 1 chain of the major histocompatibility complex class II (MHC II). The transmembrane domain of the MHC class II DQ alpha 1 chain (DQA1) assembles with the DQ beta 1 chain (DQB1) as a heterodimer through GXXXG-mediated protein-protein (Dixon et al. 2014; King and Dixon 2010; Travers et al. 1984) and the protein's sphingomyelin-C18 interaction motif (Bjorkholm et al. 2014). Indeed, using ${ }^{3} \mathrm{H}$-D-erythro-photo-sphingosine, a photo-activatable radioactive sphingolipid precursor, it was shown that DQA1 indeed interacts with a sphingolipid (Bjorkholm et al. 2014).

MHC class II molecules are key players in the adaptive immune response. An aberrant function of the MHC class II receptor is associated with a large number of autoimmune diseases such as diabetes type I and chronic inflammatory conditions (King and Dixon 2010; Tsai and Santamaria 2013). Notably, natural variants of DQ alpha 1 which correlate with an increased risk for type I diabetes include single amino acid alterations within the putative sphingolipid-binding motif of the transmembrane domain (e.g. Diaz-Horta et al. 2010; Dixon et al. 2014; Gambelunghe et al. 2007).

Therefore, by investigating if and how lipid binding to MHC class II proteins might modulate their immunological function presents a novel avenue in understanding and targeting pathological conditions such as autoimmune diseases. These facts define MHC class II molecules as proteins with important biomedical function. While molecular determinants in peptide binding of the extracellular domains of MHC II DQ proteins have in many cases been characterized in great detail (Painter and Stern 2012), the importance of the transmembrane in heterodimer assembly, the formation of distinct conformational subclasses and their relationship to biological function have been explored by biophysical approaches, site-directed mutagenesis and the analysis of epitope expression (Dixon and Roy 2019; Drake and Drake 2016). Nevertheless, many open questions remain about the roles of their transmembrane domains in assembly, trafficking, peptide loading, presentation and specifically their interactions with lipids (Anderson and Roche 2015).

In order to establish the structure of the transmembrane domains of the MHC class II alpha and beta chains in a bilayer environment, here we used a combination of CD-, ${ }^{2} \mathrm{H}$ and ${ }^{15} \mathrm{~N}$ solid-state NMR spectroscopies to establish angular restraints that can be recombined for a topological and structural analysis of membrane-associated polypeptides (Aisenbrey et al. 2006; Das et al. 2015; Gopinath et al. 2015; Michalek et al. 2013; Ramamoorthy et al. 2010). To our knowledge, for the first time the interactions with DQA1/ DQB1 and the effect of sphingomyelin on the structure and alignment of these transmembrane domains has been investigated. These structural investigations reveal a number of different topologies of the transmembrane domain that are in dynamic equilibrium. Furthermore, whereas previous studies have focused on the protein structure and dimerization $\mathbf{A Q 4} 7$ (Dixon et al. 2014; Dixon and Roy 2019; Drake and Drake 2016; King and Dixon 2010; Travers et al. 1984) here the interplay of sphingomyelin, the DQA1 and the DQB1 transmembrane domains of MHC II has been included in the investigation by monitoring changes in structure and dynamics of the lipid fatty acyl chains using ${ }^{31} \mathrm{P}$ and ${ }^{2} \mathrm{H}$ solid-state NMR spectroscopy (Dufourc 2008; Salnikov et al. 2009a). In particular, complementary structural data on a number of protein conformations and topologies have been measured in a liquid crystalline lipid bilayer environment where a dynamic picture emerges, governed by an interplay between DQA1, DQB1 and sphingolipids. By investigating the structure and topology of the polypeptide as well as the structure and dynamics of the lipids, a comprehensive picture of the structural organization of the transmembrane region of $\mathrm{MHC}$ class II proteins has been obtained. 


\section{Materials and Methods}

\section{Peptides and Lipids}

1-Palmitoyl-2-oleoyl-sn-glycero-3-phosphocholine (POPC and POPC- $\left.\mathrm{d}_{31}\right)$ and ${ }^{2} \mathrm{H}$-depleted water $(<1 \mathrm{ppm})$ were from Sigma-Aldrich (St Quentin Fallavier France), $N$-octadecanoyl-D-erythro-sphingosylphosphorylcholine (SM-C18) were purchased from Avanti Polar Lipids (Birmingham, AL), Fmoc amino acids were from NovaBiochem/Merck KGaA (Darmstadt, Germany), isotope labelled amino acids from Cortecnet (Voisins les Bretonneux, France) or Aldrich (Saint Louis, MI, USA), TentaGel-S-RAM resin from Rapp Polymer GmbH (Tübingen, Germany).

The primary peptide sequences studied in this paper are amino acids 215-244 of uniprot entry P01909:

DQA1-TMD : KK TETVV CALGL SVGLV GIVVG TVFII RGLRS KK exchanged in $4 \%$ acetic acid and the product lyophilized and stored at $-20{ }^{\circ} \mathrm{C}$ until usage.

\section{Preparation of Non-oriented Samples}

Non-oriented samples were prepared by dissolving $3 \mathrm{mg}$ of deuterated POPC (POPC-d31) and appropriate amount of peptide (0.135 $\mathrm{mg}$ of DQA1 at $1 \mathrm{~mol} \%$; $\mathrm{pH}$ adjusted to 7) and/or SM-C18 (0.15 mg, $5 \mathrm{~mol} \%)$ in HFIP. The solvent was evaporated under a stream of nitrogen and high vacuum overnight thus a film forms on the walls of the small glass tube ( $6 \mathrm{~mm}$ outer diameter). The sample was then resuspended in $15 \mu \mathrm{l}$ of $10 \mathrm{mM}$ phosphate buffer ( $\mathrm{pH} 7.1)$ by vortexing and bath sonication followed by 5 freeze/thaw cycles. The glass tube with the sample inside was then measured in

DQB1-TMD : KK QSKML SGIGG FVLGL IFLGL GLIIH HRSQK K

The transmembrane domains of the two proteins are underlined. Two lysines were added at each terminus of DQA1. The N-terminus of DQB1 was extended by two and its C-terminus by one lysine helping in the solubility and handling of the peptides.

The peptides were prepared by solid-phase peptide synthesis using a Millipore 9050 automatic peptide synthesizer, TentaGel-S-RAM resins (Rapp Polymer GmbH, Tubingen, Germany) and a fourfold excess of Fmoc-protected amino acid (NovaBiochem/Merck KGaA, Darmstadt, Germany). Fmoc-protected amino acid precursors carrying stable ${ }^{15} \mathrm{~N}$ and/or ${ }^{2} \mathrm{H}$ isotopes were inserted (Euriso-top, Paris, France or Isotec ${ }^{\circledR}$ Sigma-Aldrich St Quentin Fallavier, France) at selected positions. The crude product was cleaved from the resin and deprotected in trifluoroacetic acid (TFA)/1,2-ethanedithiol/water/triisopropylsilane $(28 / 0.75 / 0.75 / 0.3 \mathrm{v} / \mathrm{v} / \mathrm{v} / \mathrm{v})$. Thereafter, the peptide in solution was taken-up in toluene $(50 / 50)$ $(\mathrm{v} / \mathrm{v})$, the solvent evaporated and washed three times in cold ether at $4{ }^{\circ} \mathrm{C}$. Peptide purification was achieved by reverse phase HPLC (Gilson, Villiers-le-Bel, France) using an acetonitrile/water gradient and a preparative C-18 (Luna, C18-300 -5 um, Phenomenex, Le Pecq, France) or a semipreparative $\mathrm{C}-4$ column (Nucleosil C4-300 $\mathrm{-}-7 \mu \mathrm{m}$, Macherey-Nagel, Düren, Germany). The identity and purity of the final product $(>90 \%)$ were checked by analytical HPLC and MALDI mass spectrometry (MALDI-TOF Autoflex, Bruker Daltonics, Bremen, Germany). Thereafter, the product was lyophilized, the TFA counterions with a solenoid coil.

\section{Preparation of Samples for Oriented Solid-State} NMR Spectroscopy

For reconstitution of DQA1 and/or DQB1 into membranes, the appropriate amount of peptide in HFIP/water 1/1 (v/v) was added to a solution of 50-80 mg lipid (POPC or POPC/ SM-C18) in HFIP in four steps. After each step, the sample was vortexed and the solvent partially evaporated following the protocol described in Kemayo Koumkoua et al. (2014). Thereafter, the solution was spread onto ultrathin cover glasses $(8 \times 22 \mathrm{~mm}$, thickness 00; Marienfeld, Lauda-Königshofen, Germany) and dried, first in the air and thereafter in high vacuum overnight. Membranes were equilibrated at 93\% relative humidity (r.h.) using ${ }^{2} \mathrm{H}$-depleted water.

\section{Circular Dichroism}

The unoriented samples prepared for deuterium measurements (see above) containing $2 \mathrm{mg}$ POPC and the indicated amount of peptide were further diluted by adding $990 \mu \mathrm{l}$ of $10 \mathrm{mM}$ phosphate buffer ( $\mathrm{pH}$ 7.1) (1 ml of buffer in total). After 3 freeze-thaw cycles, the samples were tip sonnicated and centrifuged to remove any titanium debris from the tip. The circular dichroism spectra were measured on a Jasco J-810 spectrometer (JASCO International Co. Ltd. Tokyo,

\begin{tabular}{|l|l|l|l|l|}
\hline Journal : Large 232 & Article No : 71 & Pages : 14 & MS Code : 71 & Dispatch : 31-5-2019 \\
\hline
\end{tabular}


Japan) using a $1 \mathrm{~mm}$ cuvette (Hellma GmbH and Co. KG, Müllheim, Germany).

\section{Solid-State NMR Spectroscopy}

Proton-decoupled ${ }^{31} \mathrm{P}$ solid-state NMR spectra were acquired at $121.577 \mathrm{MHz}$ using a Bruker Avance wide-bore 300 solid-state NMR spectrometer equipped with a doubleresonance flat-coil probe (Rheinstetten, Germany). A Hahnecho pulse sequence (Rance and Byrd 1983) was used with a $\pi / 2$ pulse of $5 \mu \mathrm{s}$, a spectral width of $100 \mathrm{kHz}$, an echo delay of $40 \mu \mathrm{s}$, an acquisition time of $10.2 \mathrm{~ms}$ and a recycle delay of $3 \mathrm{~s}$. External $85 \% \mathrm{H}_{3} \mathrm{PO}_{4}$ was calibrated to $0 \mathrm{ppm}$. The temperature was set to $23^{\circ} \mathrm{C}$.

${ }^{2} \mathrm{H}$ solid-state NMR spectra of ${ }^{2} \mathrm{H}_{3}$-alanine-labelled DQA1 were acquired using a quadrupolar echo pulse sequence (Davis et al. 1976) with the following parameters: $\pi / 2$ pulse $5 \mu \mathrm{s}$, echo delay $50 \mu \mathrm{s}$, acquisition time $25.6 \mathrm{~ms}$, recycle delay $1 \mathrm{~s}$ and temperature $23{ }^{\circ} \mathrm{C}$. The spectra were recorded with a dwell time of $0.5 \mu$ s such that the echo top can be defined accurately (spectral filters at $125 \mathrm{kHz}$ ). An exponential apodization function corresponding to a line broadening of $300 \mathrm{~Hz}$ was applied before Fourier transformation. ${ }^{2} \mathrm{H}_{2} \mathrm{O}$ at $0 \mathrm{~Hz}$ was used as a reference.

For ${ }^{2} \mathrm{H}$ solid-state NMR spectra of deuterated lipids a repetition delay of $0.3 \mathrm{~s}$, an echo time of $100 \mu \mathrm{s}$, a dwell time of $0.5 \mu \mathrm{s}$ and $\mathrm{a} \mathrm{B}_{1}$ field of $41 \mathrm{kHz}$ were used. The processing included an exponential apodization with line broadening of $100 \mathrm{~Hz}$. The temperature was set to $37^{\circ} \mathrm{C}$.

Proton-decoupled ${ }^{15} \mathrm{~N}$ cross-polarization (CP) spectra were recorded $76.016 \mathrm{MHz}$ on a Bruker Avance wide-bore NMR spectrometer operating at a ${ }^{1} \mathrm{H}$ frequency of $750 \mathrm{MHz}$ using an e-free double-resonance flat-coil probe (Bechinger and Opella 1991) and a cross-polarization pulse sequence. The spectral width, acquisition time, CP contact time and recycle delay time were $100 \mathrm{kHz}, 3.9 \mathrm{~ms}, 0.8 \mathrm{~ms}$ and $3 \mathrm{~s}$, respectively. The ${ }^{1} \mathrm{H} \pi / 2$ pulse and SPINAL-64 heteronuclear decoupling field strengths were $35 \mathrm{kHz}$ (Fung et al. 2000). The ${ }^{15} \mathrm{~N}-\mathrm{G} 15-\mathrm{DQA} 1$ spectrum was acquired at a ${ }^{1} \mathrm{H}$ frequency of $300 \mathrm{MHz}$ where an adiabatic $\mathrm{CP}$ pulse sequence with the following parameters was used: $25 \mathrm{kHz}, 10.2 \mathrm{~ms}$, $0.4 \mathrm{~ms}$ and $2 \mathrm{~s}$. The temperature was set to $23{ }^{\circ} \mathrm{C}$. Prior to Fourier transformation a $100 \mathrm{~Hz}$ exponential line broadening was applied to the free induction decay. ${ }^{15} \mathrm{NH}_{4} \mathrm{Cl}$ as an external reference was set to $39.3 \mathrm{ppm}$ (Bertani et al. 2014).

\section{Analysis of Deuterium Order Parameters of Lipid Bilayers}

The deuterium order parameters $\left(S_{\mathrm{CD}}\right)$ of each $\mathrm{CD}_{2}$ and $\mathrm{CD}_{3}$ group are extracted according to $S_{\mathrm{CD}}^{i}=\frac{4}{3} \frac{h}{e^{2} q Q} \Delta^{i} v$, where $\left(e^{2} q Q / h\right)$ is the static quadrupole coupling constant
(167 kHz) for a C-D bond (Batchelder et al. 1983). Whereas the absolute values of hydrophobic thickness depend on a number of assumptions and estimates (Nagle and TristramNagle 2000), the change in thickness is more reliable and calculated according to $2 L_{0} \Delta<|S|>$, where $L_{0}$ is the length of the all-trans fatty acyl chain and $\Delta<|S|>$ the change in the average order parameter (Salnikov et al. 2009a, b).

\section{Analysis of Orientational Restraints from Oriented Solid-State NMR Spectra}

A coordinate system was defined with the tilt angle being the angle between the helix long axis and the membrane normal. A variety of $\alpha$-helical conformations with Ramachandran angles of $\left(\varphi=-65^{\circ}, \psi=-45^{\circ}\right)$ were tested as indicated in the text. The tilt and pitch angles were successively changed $(50 \times 50$ steps $)$ and the corresponding ${ }^{15} \mathrm{~N}$ chemical shift and quadrupolar splitting calculated (Michalek et al. 2013). For these calculations, the ${ }^{15} \mathrm{~N}$ chemical shift main tensor elements were $56 \mathrm{ppm}, 81 \mathrm{ppm}$ and $223 \mathrm{ppm}$ for leucine, and $46 \mathrm{ppm}, 67 \mathrm{ppm}$ and $213 \mathrm{ppm}$ for glycine (Salnikov et al. $2009 \mathrm{a}, \mathrm{b}, \mathrm{c}$ ). A quadrupolar splitting of $74 \mathrm{kHz}$ was used as a reference for the alanine ${ }^{2} \mathrm{H}_{3} \mathrm{C}$-group at ambient temperature (Batchelder et al. 1983)

Orientational heterogeneity was taken into account by using the standard deviation of a Gaussian line shape. In a first model, the peptide was static, whereas in the second approach wobbling $\left(12^{\circ}\right.$ Gaussian distribution) and azimuthal fluctuations around the helix long axis $\left(80^{\circ}\right)$ were assumed to occur in an independent fashion and taken into consideration by averaging the resonance values on the ensemble of orientations with corresponding Gaussian distributions. Closely related motional regimes have previously been found to describe well the dynamics of the transmembrane WALP23 model peptide of related dimensions (Holt et al. 2010).

\section{Results}

In this paper, $\mathrm{CD}$ spectroscopy is used to determine the secondary structure preferences of the polypeptides in membrane environments. This information is then combined with ${ }^{15} \mathrm{~N}$ solid-state NMR spectroscopy of peptides labelled with ${ }^{15} \mathrm{~N}$ at the peptide bond and reconstituted into supported lipid bilayers. The resulting ${ }^{15} \mathrm{~N}$ chemical shifts provide direct information on the alignment of the ${ }^{15} \mathrm{~N}-\mathrm{H}$ vector relative to the membrane normal thus it is possible to distinguish transmembrane helices from peptides that align parallel to the membrane normal (Bechinger and Sizun 2003). The technique also allows to monitor changes in the tilt angle of the helical domains as well as the presence of multiple topologies or alignment distributions (Bechinger et al. 
2011). Finally, the changes in lipid fatty acyl chain packing were monitored by ${ }^{2} \mathrm{H}$ solid-state NMR spectroscopy of fully deuterated palmitoyl chains of the POPC bilayers. In this manner, structural data are collected in liquid crystalline membranes revealing the secondary structure and topology of the peptides as well as their effects on the packing and phase of the surrounding lipids.

In a first step, the secondary structures of the membraneassociated DQA1 and DQB1 peptides were determined by CD spectroscopy as a function of lipid composition, the presence of the other peptide, and the peptide-to-lipid ratio. In order to allow for a direct comparison, the $\mathrm{CD}$ spectra and some of the NMR measurements discussed later were taken from the same samples. The CD spectra closely resemble each other and are all characteristic of a high degree of helical conformation (Fig. 1). In the presence of SM-C18, the per residue molar ellipticity is somewhat increased (Fig. 1b) when compared to pure POPC membranes (Fig. 1a). Furthermore, the ratios of intensities at $222 \mathrm{~nm}$ and $209 \mathrm{~nm}$ $\left(\Theta_{222} / \Theta_{209}\right)$ are somewhat higher than what is expected for single-stranded helices (Loudet et al. 2005 and references cited therein). However, related observations are also made in the presence of light scattering artefacts (Marquette and Bechinger 2018). Therefore this observation was not evaluated further.

For solid-state NMR investigations, DQA1 peptides were synthesized by solid-phase peptide synthesis with two different isotopic labelling schemes and reconstituted into POPC membranes in the presence or absence of unlabeled DQB1 and/or sphingomyelin-C18. A first sequence was synthesized with a ${ }^{15} \mathrm{~N}$ amide at the Leu16 position, reconstituted into oriented POPC phospholipid bilayers and inserted into the magnetic field of the NMR spectrometer with the membrane normal parallel to the magnetic field direction. The Leu16 position was chosen for labelling with ${ }^{15} \mathrm{~N}$ because it is a located in the core of the hydrophobic region (see sequence in the "Materials and Methods" section) thereby exhibiting a high probability of being part of the helical secondary structure observed in the CD spectra (Fig. 1).

In a first series of experiments, the peptide-to-lipid ratio was varied from 0.5 to $2 \mathrm{~mol} \%$ (Fig. 2). Under these conditions, the resulting orientation-dependent ${ }^{15} \mathrm{~N}$ solid-state NMR spectra are a direct indicator of the approximate tilt angle of $\alpha$-helical sequences relative to the membrane (Bechinger and Sizun 2003). Whereas amide ${ }^{15} \mathrm{~N}$ chemical shifts around $200 \mathrm{ppm}$ are indicative of transmembrane helix alignments, helices that orient parallel to the membrane surface are associated with values $<100 \mathrm{ppm}$. Whereas with several orientation-dependent solid-state NMR measurements from different label positions exact topologies of helical domains have been determined (Bechinger et al. 2011; Das et al. 2015; Gopinath et al. 2015; Ramamoorthy et al. 2010), the chemical shift differences from a single ${ }^{15} \mathrm{~N}$
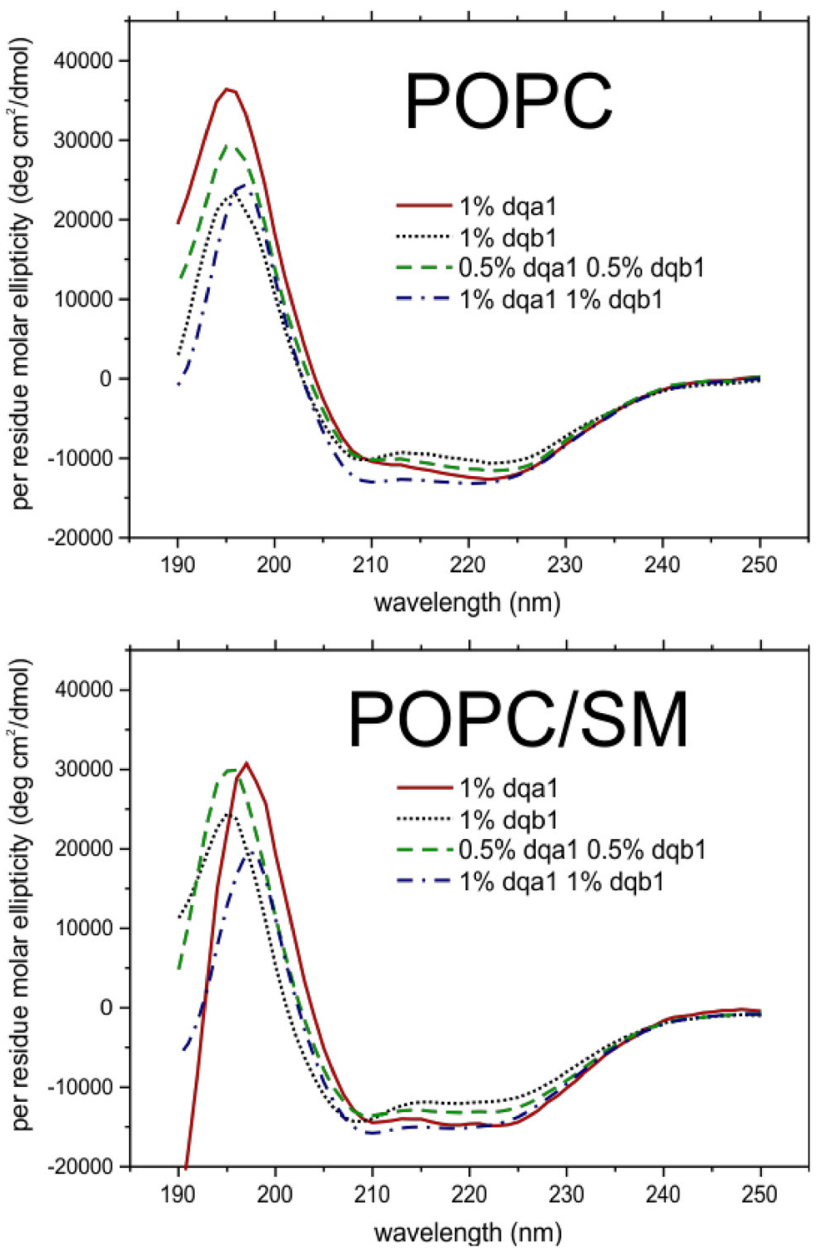

Fig. 1 Normalized circular dichroism spectra of 1\% DQA1 (solid red line), $1 \%$ DQB1 (dotted black line), mixtures of $0.5 \%$ DQA1 and $0.5 \%$ DQB1 (dashed green line) or 1\% DQA1 and 1\% DQB1 (dashdotted blue line) in small vesicles of POPC (a) and POPC/SM-C18 $95 / 5(\mathrm{~mol} / \mathrm{mol})$ (b) in the presence of $10 \mathrm{mM}$ phosphate buffer at $\mathrm{pH}$ 7.1. The same samples were also used to measure the deuterium order parameters shown in Fig. 6

labelled site allow one to monitor the presence of different topologies and orientational distributions (cf. below).

The spectra shown in Fig. 2 are characterized by three intensities whose integrals vary with the peptide-to-lipid ratio. The spectrum at $2 \mathrm{~mol} \%$ is dominated by a sharp signal intensity at $173 \pm 8 \mathrm{ppm}$. Whereas the sharp resonance confirms that the Leu16 site is part of a well-structured (helical) domain, the chemical shift value is characteristic of a transmembrane helix orientation with a tilt in the of range $35^{\circ}\left( \pm 10^{\circ}\right)$ (Fig. 2c), a value that will be further refined by taking into consideration additional measurements (cf. below). A second contribution arises at about $201 \pm 13$ ppm which is a value expected for close to perfectly transmembrane-oriented helices (tilt around $20^{\circ} \pm 10^{\circ}$ ) albeit the line width suggests a Gaussian distribution of alignments $\left( \pm 6^{\circ}\right)$ (Fig. 2c). The integrated signal intensities are suggestive of

\begin{tabular}{|l|l|l|l|l|}
\hline Journal : Large 232 & Article No : 71 & Pages : 14 & MS Code : 71 & Dispatch : 31-5-2019 \\
\hline
\end{tabular}




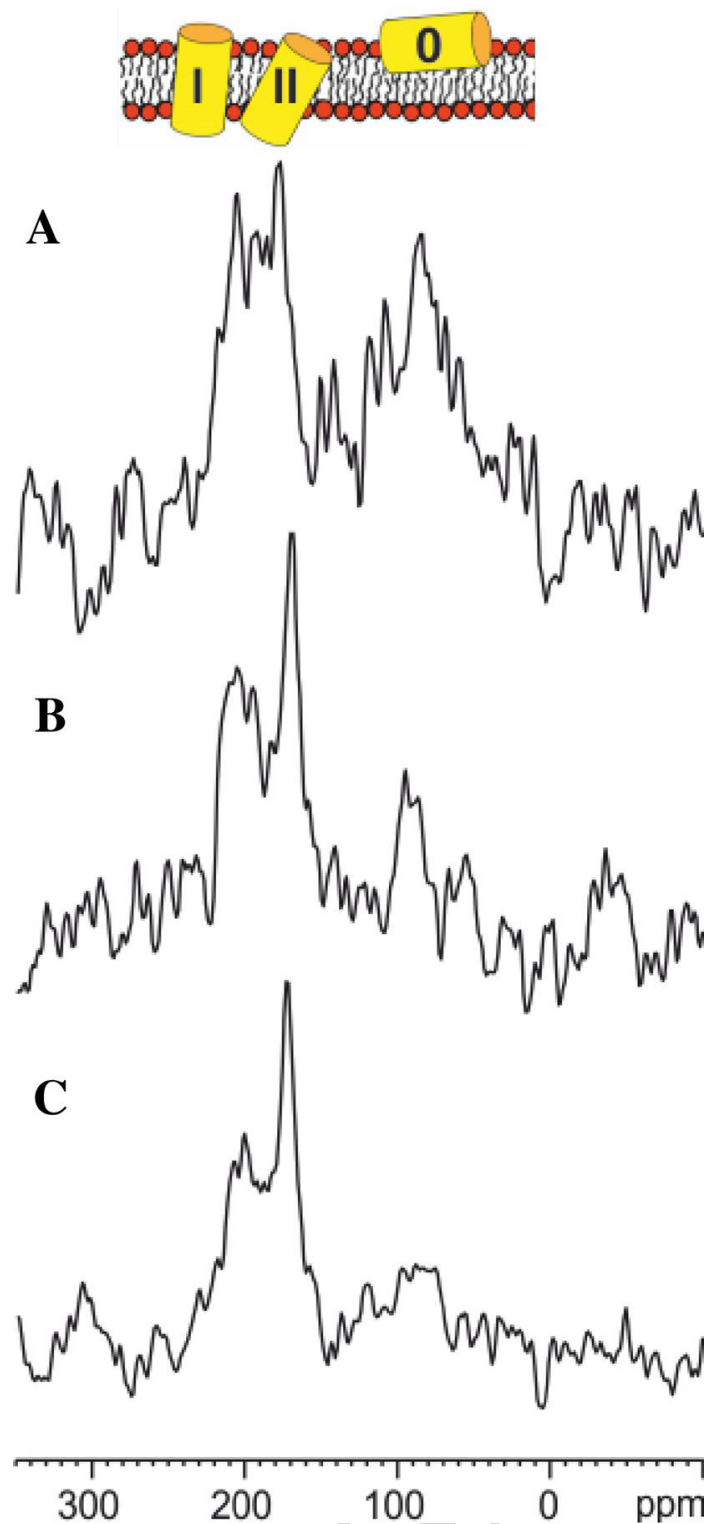

Fig. 2 Proton-decoupled cross-polarization ${ }^{15} \mathrm{~N}$ solid-state NMR spectra of $\left[{ }^{15} \mathrm{~N}\right.$-Leu16]-DQA1 reconstituted into $50 \mathrm{mg}$ POPC oriented on glass plates following the protocol described in Kemayo Koumkoua et al. (2014). The sample was inserted into the coil of the NMR probe with the sample normal parallel to the magnetic field direction. The peptide-to-lipid ratio is a $0.5 \mathrm{~mol} \%$, b $1 \mathrm{~mol} \%$ and $\mathbf{c} 2 \mathrm{~mol} \%$. The scheme on top of the figure illustrates how the ${ }^{15} \mathrm{~N}$ chemical shift correlates with the approximate helical tilt of ${ }^{15} \mathrm{~N}$ labelled polypeptides (Bechinger and Sizun 2003) and the corresponding configurational states 0 , I and II are assigned

a nearly equimolar distribution of these two peptide populations at a peptide-to-lipid ratio of $2 \mathrm{~mol} \%$ which changes in favour of the $201 \mathrm{ppm}$ population when the peptide-to-lipid ratio is reduced to 1 or $0.5 \mathrm{~mol} \%$ (Fig. 2a, b). At the same time, significant intensities appear $<100 \mathrm{ppm}$ which at $0.5 \%$ account for about half of the total signal intensity (Fig. 2a). In the following, these contributions will be assigned I

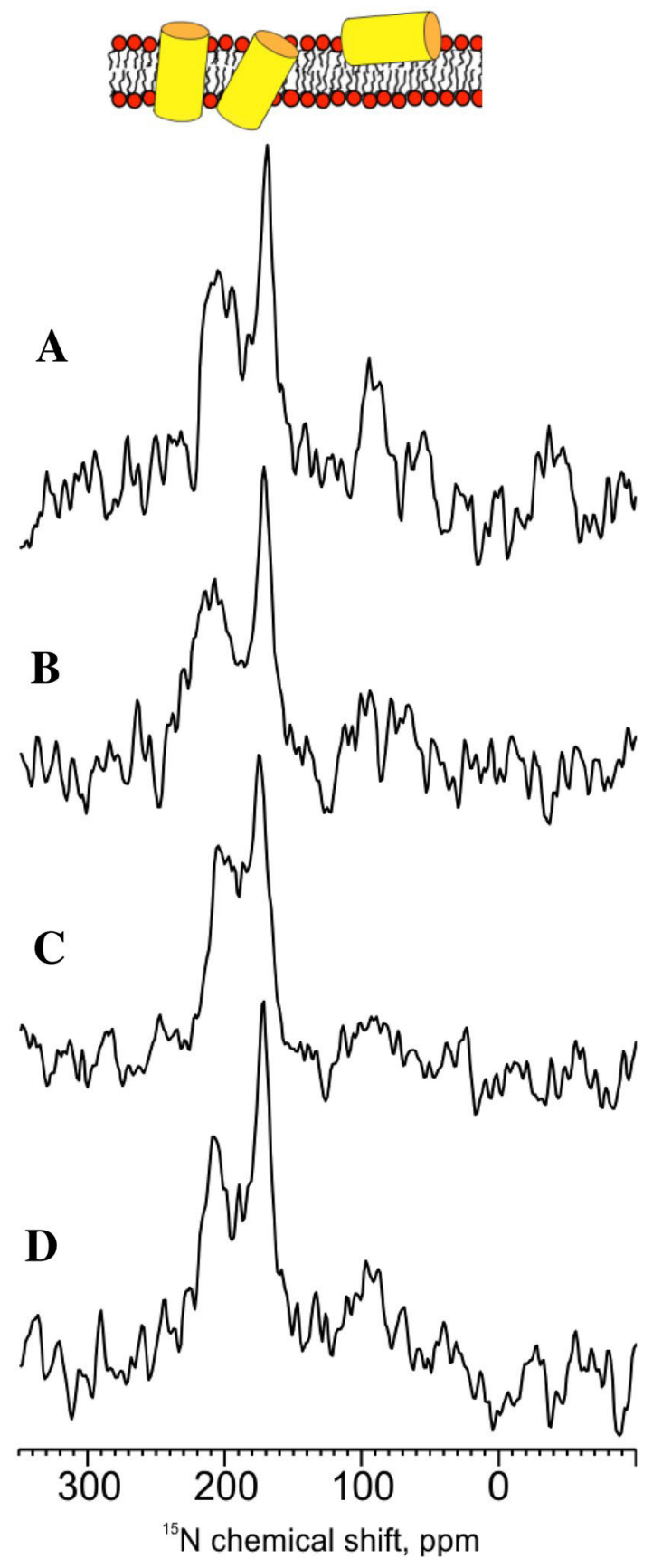

Fig. 3 Proton-decoupled cross-polarization ${ }^{15} \mathrm{~N}$ solid-state NMR spectra of a $1 \mathrm{~mol} \%$ [ ${ }^{15} \mathrm{~N}$-Leu16]-DQA1 reconstituted into $50 \mathrm{mg}$ POPC oriented on glass plates, $\mathbf{b}$ in the presence of $1 \%$ unlabelled DQB1, c $4 \mathrm{~mol} \%$ SM-C18, and d 1\% unlabelled DQB1 and $4 \mathrm{~mol} \%$ SM-C18. Reconstitution followed the protocol described in Kemayo Koumkoua et al. (2014). The sample normal is aligned parallel to the magnetic field direction. The scheme on top of the Figure illustrates how the ${ }^{15} \mathrm{~N}$ chemical shift correlates with the approximate helical tilt of ${ }^{15} \mathrm{~N}$ labelled polypeptides (Bechinger and Sizun 2003)

$(\approx 205 \mathrm{ppm})$, II $(\approx 175 \mathrm{ppm})$ and $0(<100 \mathrm{ppm})$ as shown on top of Fig. 2a. Integration of the spectra shown in Figs. 2 and 3 is shown in Figs. S1 and S2, respectively, and summarized 
in Table S1. The presence of two spectral line shapes in the transmembrane region is confirmed by a two-dimensional separated local field spectrum correlating the ${ }^{15} \mathrm{~N}$ chemical shift and the ${ }^{1} \mathrm{H}-{ }^{15} \mathrm{~N}$ dipolar coupling (Fig. S3).

Because DQA1 has been shown to interact with DQB1 (Dixon et al. 2014; Dixon and Roy 2019; Drake and Drake 2016; King and Dixon 2010; Travers et al. 1984) and sphingomyelin (Bjorkholm et al. 2014) samples with $1 \mathrm{~mol} \%{ }^{15} \mathrm{~N}$ labelled DQA1 were prepared in the presence of equimolar amounts of unlabelled DQB1 or $4 \mathrm{~mol} \% \mathrm{SM}-\mathrm{C} 18$, or both (Fig. 3). The addition of these interaction partners seems to have only subtle effects on the DQA $1{ }^{15} \mathrm{~N}$ solid-state NMR spectra. Most remarkable, when the transmembrane peaks are fitted by Lorentzian line shapes and compared to each other, the addition of both DQB1 and SM is associated with a sharpening of contribution I (203 ppm) and an increase in the ratio of intensities II/I representing the contributions at 173 and 203 ppm, respectively (Figs. 3d and S2, Table S1). Furthermore, in the presence of SM, the high-field contribution of the transmembrane peaks decreases by $4 \mathrm{ppm}$, whereas the low-field intensity increases by the same amount thereby almost merging the two transmembrane contributions (Fig. 3c).

In static-oriented membrane samples used here, the chemical shifts, dipolar and quadrupolar splitting all depend on the alignments of bonds/molecules relative to the magnetic field of the NMR spectrometer (Bechinger and Sizun 2003). Thus, one ${ }^{15} \mathrm{~N}$ labelled amide bond alone allows one to distinguish a transmembrane from an in-plane-oriented helix or from a non-oriented sample (Bechinger and Sizun 2003; Raya et al. 2011), complementary angular restraints from other positions allow one to determine helix topologies much more accurately (Bechinger et al. 2011; Das et al. 2015; Gopinath et al. 2015; Ramamoorthy et al. 2010). Whereas the amide ${ }^{15} \mathrm{~N}$ chemical shift provides a direct indicator of the approximate helical tilt angle highly complementary information on the alignment of the peptide domain which can be obtained from methyl deuterated alanines (Aisenbrey et al. 2006; Bechinger et al. 2011; Michalek et al. 2013; Resende et al. 2014). Because of fast rotation around the $\mathrm{C}_{\alpha}-\mathrm{C}_{\beta}$ bond, a single ${ }^{2} \mathrm{H}$ spectrum is obtained for all three methyl sites, whereas in uniaxially oriented membrane samples, the quadrupolar splitting is a function of the angle of the $\mathrm{C}_{\alpha}-\mathrm{C}_{\beta}$ bond relative to the membrane normal (coincident with the magnetic field of the NMR spectrometer). The only alanine in the hydrophobic region of DQA 1 is located at position 9 and this residue was therefore methyl deuterated for solid-state NMR investigations (see sequence in "Materials and Methods" section).

Thus, the DQA1 transmembrane domain was synthesized carrying a ${ }^{15} \mathrm{~N}$ label at position Gly 15 and ${ }^{2} \mathrm{H}_{3}$-Ala9. The peptide was reconstituted into oriented bilayers and investigated by solid-state NMR spectroscopy (Fig. 4). The corresponding ${ }^{15} \mathrm{~N}$ solid-state NMR spectrum encompasses a relatively broad intensity at about $178 \mathrm{ppm}$ and additional resonance intensities with a maximum at 77 ppm (Fig. 4a). It is possible that also in this case, where the label is only removed by a single amino acid position when compared to the spectra shown in Figs. 2 and 3, the transmembrane helical signal at $178 \mathrm{ppm}$ represents two contributions that add up into a broad spectral line (line width at half height $30 \mathrm{ppm})$.
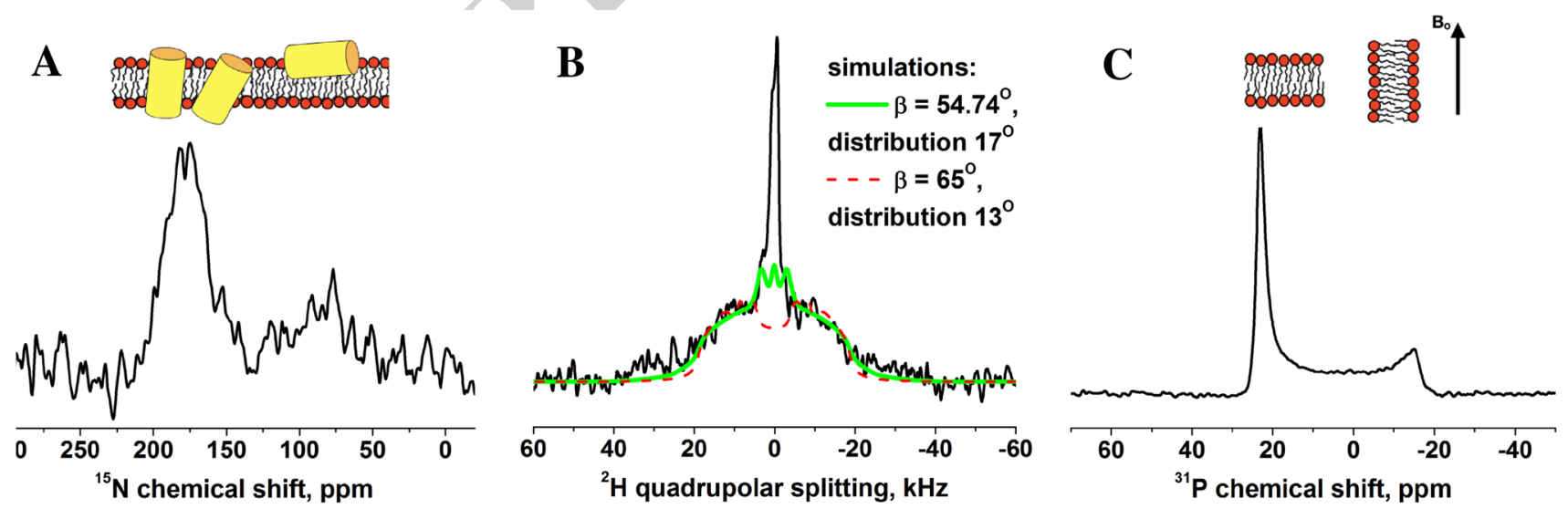

Fig. 4 a Proton-decoupled ${ }^{15} \mathrm{~N}$, b ${ }^{2} \mathrm{H}$ and c proton-decoupled ${ }^{31} \mathrm{P}$ solid-state NMR spectra of $0.9 \mathrm{~mol} \%\left[{ }^{15} \mathrm{~N}-\mathrm{Gly} 15,{ }^{2} \mathrm{H}_{3}\right.$-Ala9]-DQA1 reconstituted into POPC/SM-C18 95/5 mol/mol and oriented on glass plates. Reconstitution followed the protocol described in Kemayo Koumkoua et al. (2014) and hydration was with deuterium-depleted water $\left(10^{-4} \%\right)$. The sample normal is aligned parallel to the magnetic field direction. In (b) the central ${ }^{2} \mathrm{H}$ spectral intensities arise from residual deuterium in water. The thin dotted red and thick green lines represent simulations of the peptide intensities when the $\mathrm{C}_{\alpha}-\mathrm{C}_{\beta}$ bond is oriented at $65^{\circ}\left(\mathrm{SD} 13^{\circ}\right)$ or at the magic angle (SD $\left.17^{\circ}\right)$ relative to the magnetic field direction/sample normal, respectively. The schemes on top of $\mathbf{a}$ and $\mathbf{c}$ illustrate how the ${ }^{15} \mathrm{~N}$ and ${ }^{31} \mathrm{P}$ chemical shifts correlate with the approximate helical tilt of ${ }^{15} \mathrm{~N}$ labelled polypeptides (Bechinger and Sizun 2003) and the phospholipid alignment relative to the magnetic field $B_{\mathrm{o}}$ (Bechinger and Salnikov 2012), respectively

\begin{tabular}{|l|l|l|l|l|}
\hline Journal : Large 232 & Article No : 71 & Pages : 14 & MS Code : 71 & Dispatch : 31-5-2019 \\
\hline
\end{tabular}


The ${ }^{2} \mathrm{H}$ solid-state NMR spectrum of ${ }^{2} \mathrm{H}_{3}$-Ala9 after reconstitution of DQA1 in oriented lipid membranes exhibits a broad distribution of intensities covering about $30 \mathrm{kHz}$ (Fig. 4b). Two simulations that fit the spectra reasonably well are also shown. The spectrum can be reproduced by an orientation of the $\mathrm{C}_{\alpha}-\mathrm{C}_{\beta}$ bond at about $60^{\circ}$ relative to the magnetic field direction/membrane normal with a Gaussian distribution of around $15^{\circ}$. Because in this angular range the quadrupolar splitting is very sensitive to changes in this angle, even a modest distribution results in broad spectral line shapes (Aisenbrey and Bechinger 2004; Bechinger et al. 2011).

When the ${ }^{31} \mathrm{P}$ solid-state NMR spectra of the same macroscopically oriented samples are investigated, predominant intensities are observed at $30 \mathrm{ppm}$ (Figs. 4c, S4) indicative of phosphatidylcholine membranes in their liquid crystalline state where the lipids are aligned parallel to the membrane normal (Bechinger and Salnikov 2012). Some intensities extend to $-15 \mathrm{ppm}$ indicative of some orientational disorder at the level of the lipid head group which could arise from regions with global misalignments and/or head groups with different alignments and/or conformations (Bechinger and Salnikov 2012; Kim et al. 2009). Notably, this effect is most pronounced for samples prepared with DQB1 (Fig. S4B, D). In these samples, there is also an intensity around $20 \mathrm{ppm}$ suggestive of a phospholipid population exhibiting a reduced chemical shift anisotropy. Because these samples also carry twice as much peptide, this effect may be unspecific and will need further investigation. In contrast, the two samples containing SM-C18 exhibit a somewhat improved orientation of the ${ }^{31} \mathrm{P}$ NMR spectra (Fig. S4C, D) when compared to the corresponding samples without SM-C18 (Fig. S4A, B).

The orientational restraints from the Ala9 quadrupolar splitting as well as the Gly 15 and Leu $16{ }^{15} \mathrm{~N}$ chemical shifts all have to agree with a single topology of the DQA1 helix. To this end, the alignment relative to the membrane normal (magnetic field direction) of an ideal helix was systematically varied in steps of $2^{\circ}$ for both the azimuthal and the tilt angles and the corresponding quadrupolar splitting and chemical shifts calculated (Fig. 5). The angular pairs where the experimental value including some error bar correlating with the spectral line width agree with the simulated values are shown in the restriction plots shown in Fig. 6. Here, the broad quadrupolar Ala9 spectrum is composed of a large range of splittings, therefore, it provides only little restriction of the topological space (grey areas). In contrast, the
Fig. 5 Analysis of NMR topological restraints for DQA1 reconstituted into mechanically oriented POPC/SM (95/5) membranes at about $1 \mathrm{~mol} \%$. The topological restraints from each NMR measurement are shown for ${ }^{15} \mathrm{~N}$-Gly 15 in blue $(178 \pm 15 \mathrm{ppm})$, for ${ }^{15} \mathrm{~N}$-Leu 16 in red $(205 \pm 13$ ppm; $\mathbf{a}$ and c) or in brown $(172 \pm 8 \mathrm{ppm}$, b and d), and for ${ }^{2} \mathrm{H}_{3}$-Ala9 in grey $(0-34 \mathrm{kHz})$. The restraints were obtained assuming either a static peptide alignment (a, b) or rocking and wobbling motions of the helix (resulting in a Gaussian distribution of $12^{\circ}$ and $80^{\circ}$, respectively, $\mathbf{c}$ and d). In the case of ${ }^{15} \mathrm{~N}$ simulations, the thick central line represents the main intensity, two additional restrictions were calculated from the standard deviation to take into account orientational distributions. These are indicated by thin lines of the same colour. The restraints common to all three measurements are shown in dark red or dark brown, respectively (c, d)
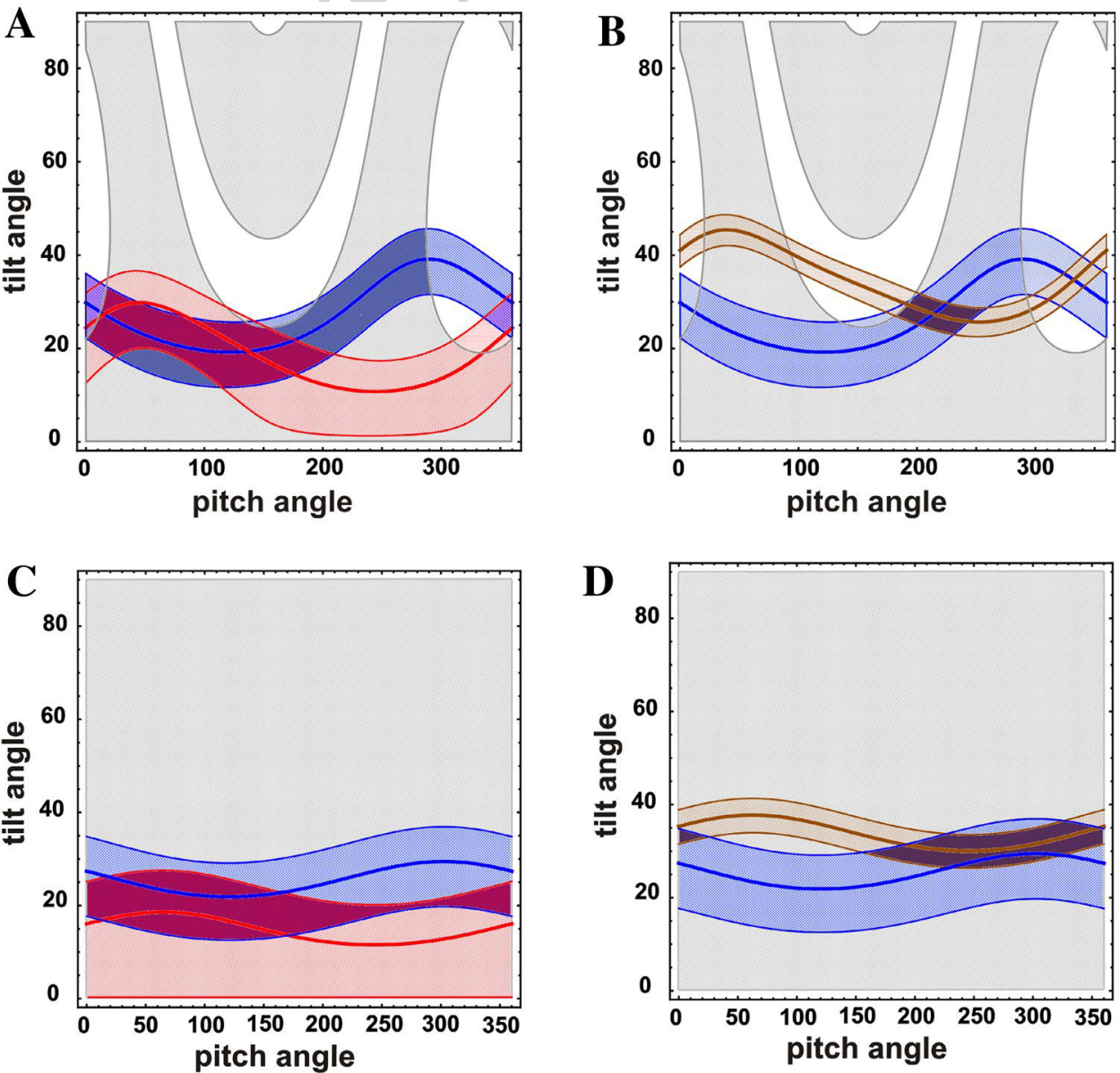


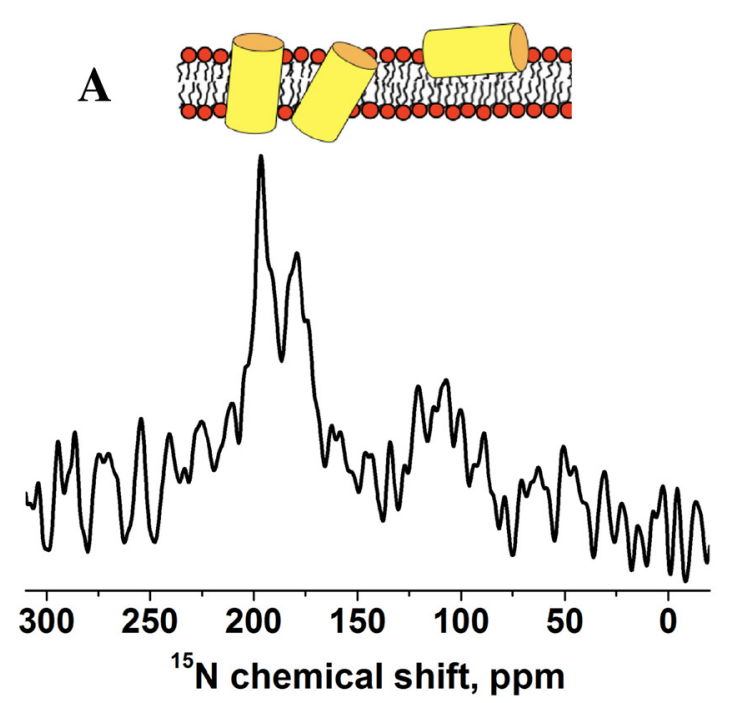

Fig. 6 Proton-decoupled cross-polarization ${ }^{15} \mathrm{~N}$ (a) and Hahn-echo ${ }^{31} \mathrm{P}$ solid-state NMR spectra (b) of $1 \mathrm{~mol} \%$ [ ${ }^{15} \mathrm{~N}$-Leu19]-DQB1 reconstituted into $40 \mathrm{mg}$ POPC oriented on glass plates in the presence of $5 \mathrm{~mol} \% \mathrm{SM}-\mathrm{C} 18$. Reconstitution followed the protocol described in Kemayo Koumkoua et al. (2014). The sample normal is aligned parallel to the magnetic field direction. Temperature

${ }^{15} \mathrm{~N}$ chemical shifts of Gly15 (blue) and of Leu16 (red for the $205 \mathrm{ppm}$ and brown for the $172 \mathrm{ppm}$ intensity) define the tilt angles reasonably well, resulting in angles for the two peptide populations of about $20^{\circ}$ and $30^{\circ}$, respectively.

Complementary information was obtained by investigating DQB1 labelled with ${ }^{15} \mathrm{~N}$ at Leu19. Also in this case, the transmembrane intensities dominate with a contribution at $179 \pm 8 \mathrm{ppm}$ and another one at $195.5 \pm 5.5 \mathrm{ppm}$ (peak maximum at $197 \mathrm{ppm}$ ) (Fig. 6a). The corresponding ${ }^{31} \mathrm{P}$ solid-state NMR spectrum is indicative of a well-aligned sample (Fig. 6b).

In a final series of experiments, the effects of the peptides on the lipids were investigated using ${ }^{2} \mathrm{H}$ solid-state NMR spectroscopy, where the POPC lipids were deuterated throughout the palmitoyl chain. From each deuterated $\mathrm{CD}_{2}$ and the terminal $\mathrm{CD}_{3}$ segment, a deuterium quadrupole doublet is observed (Fig. 1 in Salnikov et al. 2009b) which for the pure lipid bilayer decreases in a continuous fashion when entering the hydrophobic membrane interior. The largest quadrupolar splittings are observed for the six $\mathrm{CD}_{2}$ chains closest to the lipid head group and the contributions of the individual segments sum up into spectra such as shown in Fig. 7a, b. The deuterium quadrupole splitting is directly proportional to the deuterium order parameter which takes into account the averaging of the static quadrupolar splitting by conformational dynamics (Fig. 7c, d). When working with a perdeuterated palmitoyl chain it is assumed that even after addition of peptide, a membrane-active compound or another lipid the largest

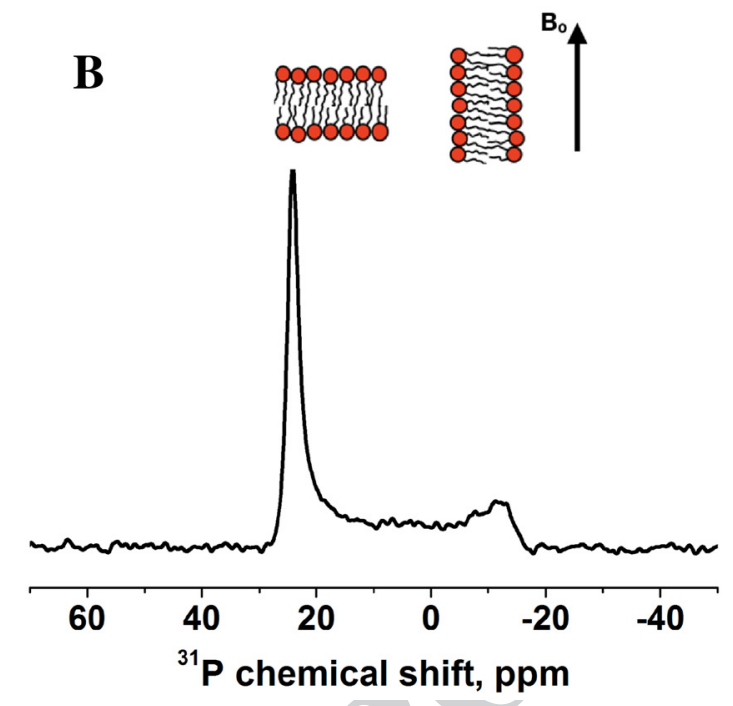

$20{ }^{\circ} \mathrm{C}$. The schemes on top of the panels illustrate how the ${ }^{15} \mathrm{~N}$ and ${ }^{31} \mathrm{P}$ chemical shifts correlate with the approximate helical tilt of ${ }^{15} \mathrm{~N}$ labelled polypeptides (Bechinger and Sizun 2003) and the phospholipid alignment relative to the magnetic field $\mathrm{B}_{\mathrm{o}}$ (Bechinger and Salnikov 2012), respectively

quadrupolar splitting is associated with a $\mathrm{CD}_{2}$ segment closest to the ester bond. The first few segments all show a similarly large splitting thus the order parameters form a plateau, when plotted as a function of the segment number. Thereafter, they continuously decrease towards the methyl group (Fig. 7c, d).

The order parameters of the plateau exhibit values of 0.201 for POPC, 0.199 in the presence of $5 \mathrm{~mol} \% \mathrm{SM}, 0.198$ upon addition of $1 \mathrm{~mol} \%$ DQA 1 and 0.196 in the presence of 1 mol\% DQB1 (Fig. 7c, d). A more convenient representation of the peptide and SM induced changes is obtained when the relative order parameters are plotted by calculating the ratio of the absolute order parameter relative to the one of pure POPC (Fig. 7e-h).

Addition of either $5 \mathrm{~mol} \% \mathrm{SM}-\mathrm{C} 18,1 \mathrm{~mol} \% \mathrm{DQA} 1$ or $1 \mathrm{~mol} \%$ DQB1 results in only small changes of the palmitoyl order parameter (Fig. 7e, f). However, when SM and one of the peptides are added simultaneously, the order of the palmitoyl segments more deeply buried inside the bilayer (segments $>6$ ) is reduced by $>10 \%$ in case of DQA1 (Fig. 7e) and by about $17 \%$ for DQB 1 (Fig. 7f).

In a related manner, in the absence of SM, little changes occur when equimolar mixtures of DQA1 and DQB1 are added (Fig. 7g). However, when both peptides and SM-C18 are present in the membrane at a total peptide concentration of $1 \%$, the decrease in the order of positions 7 to 15 is almost 20\% (Fig. 7g). Notably, DQA1/DQB1 and DQB1 alone (both about $-17 \%$ ) have a larger effect than DQA1 $(-10 \%)$ (Fig. 7h).

\begin{tabular}{|l|l|l|l|l|}
\hline Journal : Large 232 & Article No : 71 & Pages : 14 & MS Code : 71 & Dispatch : 31-5-2019 \\
\hline
\end{tabular}


A
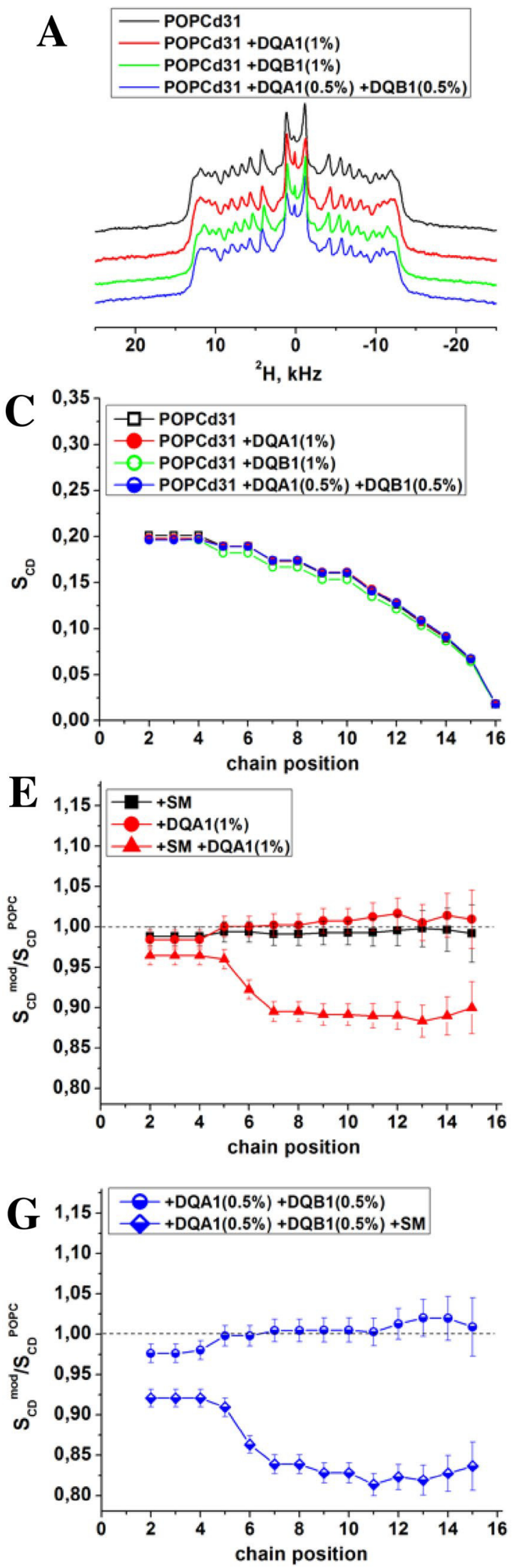

B
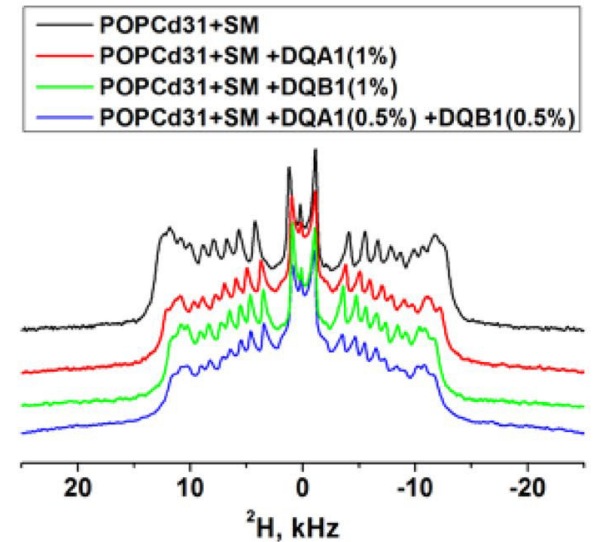

D
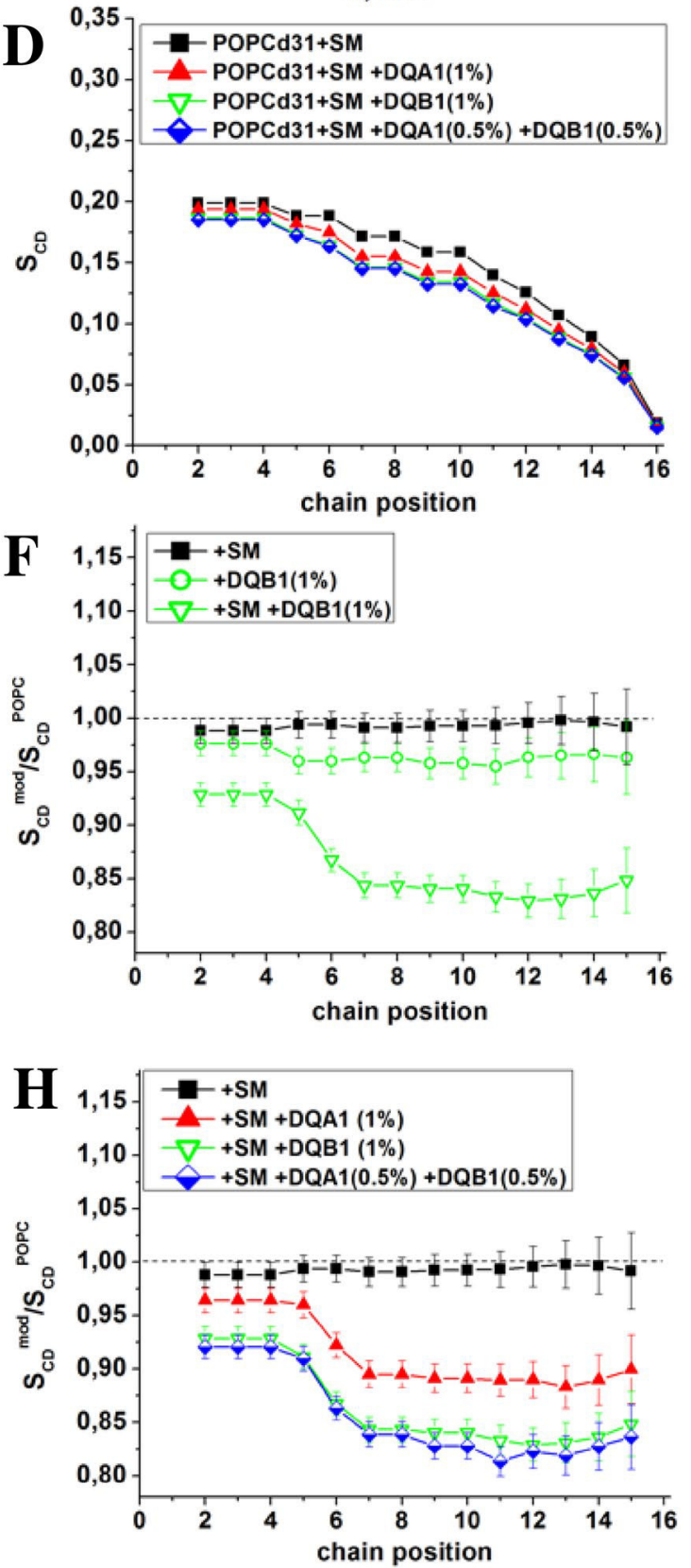
4 Fig. $7{ }^{2} \mathrm{H}$ solid-state NMR spectra of POPC- $\mathrm{d}_{31}$ (a) or POPC- $\mathrm{d}_{31} /$ SM-C18 95/5 mol/mol (b), the corresponding absolute (c, d) and relative order parameters $(\mathbf{e}-\mathbf{h})$ in the presence of SM-C18, DQA1, DQB1, $0.5 \mathrm{~mol} \%$ each of DQA1 and DQB1, or both peptides at $1 \mathrm{~mol} \%$. The error to read out the quadrupolar splittings is estimated $\pm 150 \mathrm{~Hz}$ and does not exceed the size of the symbols in (c, d). For the relative order parameters it propagates as shown by the error bars in $(\mathbf{e}-\mathbf{h})$

A quantitative evaluation of the average changes can be obtained by converting the order parameter of the whole chain into the hydrophobic thickness of the bilayer according to the equations provided in the "Materials and Methods" section. The results of such considerations are summarized in Table 1 indicating a pronounced thinning effect in particular by DQB1 when SM is present.

\section{Discussion}

In order to better understand the regulatory interactions between different subunits of the MHC II receptor and its surrounding lipids, the DQA1 transmembrane domain was reconstituted into lipid bilayers and investigated by $\mathrm{CD}$ - and static-oriented solid-state NMR spectroscopies (Figs. 1, 2, 3,4 and 5). The ${ }^{15} \mathrm{~N}$ chemical shift spectra of ${ }^{15} \mathrm{~N}$ labelled Gly15 and Leu16 exhibit intensities characteristic of transmembrane helical sequences (Bechinger and Sizun 2003). Notably, whereas the Leu $16{ }^{15} \mathrm{~N}$ signal intensity is characterized by two spectral contributions at $175 \mathrm{ppm}$ and $205 \mathrm{ppm}$ (Figs. 2 and 3), the Gly 15 resonance exhibits a broad spectral line centred at $180 \mathrm{ppm}$ (Fig. 4) suggesting that also in this case the resonance represents at least two topological configurations with different tilt/pitch angles. The analysis of solid-state NMR angular restraints shown in Fig. 5 is suggestive that the $35 \mathrm{ppm}$ chemical shift difference of the two peaks arising from the Leu16 site (Fig. 2) is due to an about $10-20^{\circ}$ difference in tilt angle, due to very different pitch angles or a combination thereof (Fig. 5). The concentration-dependent shift of the Leu $16{ }^{15} \mathrm{~N}$ intensities from predominantly $210 \mathrm{ppm}$ at $0.5 \mathrm{~mol} \%$ peptide concentration to predominantly $175 \mathrm{ppm}$ when the peptide-to-lipid ratio is increased (Figs. 2 and S1, Table S1) is suggestive that the DQA1 transmembrane domain oligomerizes thereby adopting a more tilted helix alignment relative to the membrane normal (Fig. 5) and agrees with the previously observed formation of homodimers using biochemical assays and FRET (King and Dixon 2010).

Notably, a strongly tilted (about $30^{\circ} \pm 10^{\circ}$ ) transmembrane alignment of DQA1 has also been observed in DMPC/DHPC bicelles (Salnikov et al. 2019). The addition of SM-C18 or of equimolar DQB1 has little effect on the integrals of DQA1 signal intensities (Fig. 3b, c). Addition of both SM-C18 and DQB1 results in an increase in the integral of the tilted configuration when compared to the sharpened 205 ppm signal (Fig. 3d). It thus appears that SM-C18 promotes the formation of DQA1/DQB1 heterodimers analogous to the increase in homodimer formation of p24 carrying a homologous SM-C18 recognition sequence (Contreras et al. 2012). Indeed, it has been shown that the p24 type I transmembrane protein exists either as a monomer or a dimer in the early secretory pathway (Derganc et al. 2013; Jenne et al. 2002) where only the dimer triggers COPI vesicle budding by recruiting the COPI coat component coatomer (Bethune et al. 2006; Langer et al. 2008; Reinhard et al. 1999).

Interestingly at $<1 \mathrm{~mol} \%$ DQA 1 concentrations significant intensities also appear at $<100 \mathrm{ppm}$ suggesting a fur- $\mathbf{A Q 5}_{3}$ ther equilibrium connecting the in-plane-oriented peptide (population 0) with a transmembrane orientation (Figs. 2a, $4 \mathrm{a}$ and 8 ). Notably, the ${ }^{31} \mathrm{P}$ solid-state NMR spectrum is the best aligned in the peptide concentration series shown in Fig. 2 indicating a good uniaxial orientation of the sample (Fig. S4C) in agreement with the general observation of a more uniform alignment in the absence of peptide or at low peptide-to-lipid ratios (Bechinger and Salnikov 2012; Harzer 2000). Unfortunately, a quantitative analysis of the signal $<100 \mathrm{ppm}$ (population 0 ) is difficult because the line is broad and distorted by the noise level.

The spectrum obtained with DQB1 has related characteristics than those described for DQA1 (Fig. 6a), an observation that has also been made in bicellar environments (Salnikov et al. 2019). It is notable that both sequences encompass GxxxG motifs that have been identified to promote dimerization within membrane environments (Dixon et al. 2014; Drake and Drake 2016; King and Dixon 2010; Russ et al. 2000; Travers et al. 1984). Previous structural studies of dimers interacting through the GxxxG motif were characterized by relatively high crossing angles (Itkin et al. 2017; Sato et al. 2009; Smith et al. 2002) in agreement with the tilted arrangement observed here (Figs. 2, 3, 4 and 5)

The data presented in this paper thereby indicate a topological equilibrium between two transmembrane states, where the concentration-dependent behavior shown in Fig. 2 suggests a dimerization albeit we do not know the exact size of the complexes (Fig. 8). Furthermore, an equilibrium exists between in-plane-oriented peptides and the transmembrane states (Figs. 2 and 8). Although here we only studied the isolated transmembrane domain, it should be noted that the full-length DQA1 and DQB1 proteins extend only by few amino acids beyond the hydrophobic region of the membrane, probably barely extending beyond the bilayer interface (Travers et al. 1984). Therefore, transitions from the in-planar to the transmembrane state only require the transfer of a few amino acids. Equilibria between in-plane and transmembrane configurations have previously also been observed for the $\mathrm{C}$-terminal $\mathrm{Bcl}-\mathrm{x}_{\mathrm{L}}$ hydrophobic sequence

\begin{tabular}{|l|l|l|l|l|}
\hline Journal : Large 232 & Article No : 71 & Pages : 14 & MS Code : 71 & Dispatch : 31-5-2019 \\
\hline
\end{tabular}


Table 1 Estimated hydrophobic bilayer thickness $(\AA)$ of peptide-free membranes, and changes in hydrophobic thickness upon addition of peptides at $37^{\circ} \mathrm{C}$

\begin{tabular}{lll}
\hline & POPCd31 & $\begin{array}{l}\text { POPCd31/ } \\
\text { SM-C18 }\end{array}$ \\
\hline No peptide & 27.3 & 27.0 \\
DQA1 1 mol\% & -0.2 & -0.4 \\
DQB1 1 mol\% & --0.4 & -0.65 \\
DQA1/DQB1 $0.5 / 0.5 \mathrm{~mol} \%$ & -0.4 & -0.7 \\
\hline
\end{tabular}

The hydrophobic thickness is calculated from the ${ }^{2} \mathrm{H}$ order parameters as described in the "Materials and Methods" section. The estimated experimental precision in hydrophobic thickness is $\backslash \pm 0.1 \AA$ (see Salnikov et al. 2009b for details)

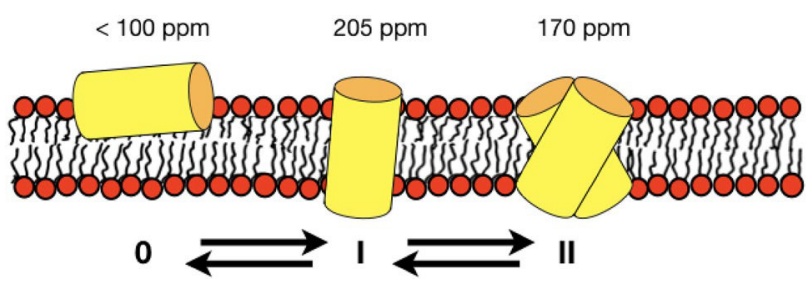

Fig. 8 Schematic presentation of the equilibria governing the DQA1 topology and tentative assignment of the corresponding ${ }^{15} \mathrm{~N}$ chemical shifts of $\left[{ }^{15} \mathrm{~N}\right.$-Leu16]-DQA1. Here a first equilibrium between the surface-associated and the transmembrane monomer is assumed, followed by a second equilibrium between the transmembrane monoand dimer although the exact size of the complexes remains unknown from the experiments presented in this paper. The numberings of the configurational states is also shown: 0 for surface-associated, I for transmembrane monomer and II for transmembrane dimer

which serves as a reversible membrane anchor of this large protein (Aisenbrey et al. 2007), as well as for other predominantly hydrophobic sequences such as alamethicin (Huang 2000; Salnikov et al. 2010), helical model peptides (Bechinger 2001; Perrone et al. 2014; Vogt et al. 2000) or antimicrobial $\beta$-sheet peptides (Hong 2006; Salnikov et al. 2011).

When the influence of the DQA1 or DQB1 transmembrane domains on the POPC- $\mathrm{d}_{31}$ order parameter is analysed, the peptides alone have very little effect on the membrane packing (changes $<5 \%$; Fig. $7 \mathrm{e}-\mathrm{h}$ ). The data thereby agree with previous investigations of deuterium order parameters in the presence of hydrophobic transmembrane sequences, including p24 for which an increase of the POPC order parameter was observed (Salnikov et al. 2019, 2009b). However, in combination with SM-C18, the addition of $1 \mathrm{~mol} \%$ DQA1 or DQB1 resulted in a significant decrease of the POPC palmitoyl chain order within the core region of the membrane (beyond segment 6). The decrease in order parameter is considerably more pronounced for DQB1 (-17\%, Fig. 7f, Table 1) when compared to DQA1 (-11\%, Fig. 7e, Table 1).
When the two peptides are added in combination, a decrease in order parameters is observed in the presence of SM which is dominated by DQB1 (Fig. 7h). Therefore, DQB1 in combination with the SM lipid exerts a membrane disordering effect similar to changes that have previously been observed for linear cationic amphipathic antimicrobial peptides such as magainins (Aisenbrey et al. 2019; Grage et al. 2016; Hallock et al. 2003; Harmouche and Bechinger 2018; Kim et al. 2009; Salnikov et al. 2010). Whereas these antimicrobial peptides are oriented along the bilayer interface where they induce pronounced positive curvature strain (Aisenbrey et al. 2019; Bechinger 2009), DQA1 and DQB1 adopt transmembrane but strongly tilted arrangements (Fig. 8) in DMPC bicelles (Salnikov et al. 2019) as well as in POPC or POPC/SM 95/5 lipid bilayers (Figs. 2b, c, 3, 4a, 5 and 6). A protein dimer associated with sphingomyelin lipids potentially resembles an hourglass-shaped transmembrane protein, which can have a similar effect in disordering the POPC lipid packing at the membrane interior.

Furthermore, it should be considered that the membrane disordering effect does not correlate with the presence of the highly specific SM-C18 recognition sequence (DQB1 has a stronger effect than DQA1) or with a pronounced shift in monomer-dimer equilibrium (Fig. 3). Although $5 \mathrm{~mol} \%$ sphingomyelin causes only small changes in the packing of the POPC palmitoyl chain (Fig. 7a-d), it is possible that SM-C18 pre-conditions the POPC membrane for the membrane disordering effects of DQA1 and DQB1 visible in ${ }^{2} \mathrm{H}$ (Fig. 7e-g) and in ${ }^{31} \mathrm{P}$ solid-state NMR spectra (Fig. S4). It remains possible that $\mathrm{SM}$ associates with the transmembrane domains in a manner unrelated to the recognition sequence and/or that the physico-chemical properties of the membrane are affected by the sphingolipid thus it becomes more reactive to the membrane disruptive properties of the transmembrane domains.

In conclusion, here for the first time, the interactions of sphingomyelin on the structures and topologies of the transmembrane domains of DQA1 and DQB1 have been investigated by biophysical and structural approaches including the effects the proteins have on the lipid bilayer packing. The data reveal at least three topological states of the MHC II transmembrane helical domains (Fig. 8). The concentrationdependent spectral line shapes are suggestive of equilibria connecting a configuration where the polypeptide chain aligns parallel to the surface with at least two distinct transmembrane orientations probably representing a dimer of strongly tilted helices and a more upright monomer (Fig. 8). Whereas the transmembrane domains have very little effects on the molecular order of the POPC bilayer together with $5 \mathrm{~mol} \%$ SM-C18 a positive curvature strain result that causes membrane disorder in the bilayer centre in particular in the presence of DQB1. In this manner, SM can potentially have 
an effect also on the protein-protein interactions and the regulation of MHC II.

Acknowledgements The discussions with Britta Brügger and Thomas Kupke on p24, MHC II and in particular DQA1 and its specific interactions with sphingomyelin are gratefully acknowledged. We thank Arnaud Marquette for his help with first CD spectra.

Author Contributions ES and CA designed and performed the experiments and analysed data, BB helped in the design the experiments and in the analysis and wrote the paper.

Funding We are grateful for the financial contributions of the Agence Nationale de la Recherche (Projects ProLipIn 10-BLAN-731, membraneDNP 12-BSV5-0012, MemPepSyn 14-CE34-0001-01, InMembrane 15-CE11-0017-01 and the LabEx Chemistry of Complex Systems 10-LABX-0026_CSC), the University of Strasbourg, the CNRS, the Région Alsace and the RTRA International Center of Frontier Research in Chemistry. BB thanks the Institut Universitaire de France for support and for providing additional time for research.

\section{Compliance with Ethical Standards}

Conflict of interest All authors declare that they have no conflict of interest.

Ethical Approval This article does not contain any studies with human participants or animals performed by any of the authors.

\section{References}

Aisenbrey C, Bechinger B (2004) Tilt and rotational pitch angles of membrane-inserted polypeptides from combined ${ }^{15} \mathrm{~N}$ and $2 \mathrm{H}$ solid-state NMR spectroscopy. Biochemistry 43:10502-10512

Aisenbrey C, Sizun C, Koch J, Herget M, Abele U, Bechinger B, Tampe R (2006) Structure and dynamics of membrane-associated ICP47, a viral inhibitor of the MHC I antigen-processing machinery. $\mathrm{J}$ Biol Chem 281:30365-30372

Aisenbrey C, Sudheendra US, Ridley H, Bertani P, Marquette A, Nedelkina S, Lakey JH, Bechinger B (2007) Helix orientations in membrane-associated Bcl-XL determined by ${ }^{15} \mathrm{~N}$ solid-state NMR spectroscopy. Eur Biophys J 37:71-80

Aisenbrey C, Marquette A, Bechinger B (2019) The mechanisms of action of cationic antimicrobial peptides refined by novel concepts from biophysical investigations. In: Matsuzaki K (ed) Antimicrobial peptides, advances in experimental medicine and biology. Springer, Singapore

Anderson HA, Roche PA (2015) MHC class II association with lipid rafts on the antigen presenting cell surface. Biochim Biophys Acta 1853:775-780

Batchelder LS, Niu H, Torchia DA (1983) Methyl reorientation in polycrystalline amino acids and peptides: a $2 \mathrm{H} \mathrm{NMR} \mathrm{spin} \mathrm{lattice}$ relaxation study. J Am Chem Soc 105:2228-2231

Bechinger B (2001) Membrane insertion and orientation of polyalanine peptides: a ${ }^{15} \mathrm{~N}$ solid-state NMR spectroscopy investigation. Biophys J 82:2251-2256

Bechinger B (2009) Rationalizing the membrane interactions of cationic amphipathic antimicrobial peptides by their molecular shape. Curr Opin Colloid Interface Sci Surf 14:349-355

Bechinger B, Opella SJ (1991) Flat-coil probe for NMR spectroscopy of oriented membrane samples. J Magn Reson 95:585-588
Bechinger B, Salnikov ES (2012) The membrane interactions of antimicrobial peptides revealed by solid-state NMR spectroscopy. Chem Phys Lipids 165:282-301

Bechinger B, Sizun C (2003) Alignment and structural analysis of membrane polypeptides by ${ }^{15} \mathrm{~N}$ and $31 \mathrm{P}$ solid-state NMR spectroscopy. Concepts Magn Reson 18A:130-145

Bechinger B, Resende JM, Aisenbrey C (2011) The structural and topological analysis of membrane-associated polypeptides by oriented solid-state NMR spectroscopy: established concepts and novel developments. Biophys Chem 153:115-125

Bertani P, Raya J, Bechinger B (2014) ${ }^{15} \mathrm{~N}$ chemical shift referencing in solid state NMR. Solid-State NMR Spectrosc 61-62:15-18

Bethune J, Kol M, Hoffmann J, Reckmann I, Brügger B, Wieland F (2006) Coatomer, the coat protein of COPI transport vesicles, discriminates endoplasmic reticulum residents from p24 proteins. Mol Cell Biol 26:8011-8021

Bjorkholm P, Ernst AM, Hacke M, Wieland F, Brugger B, von Heijne G (2014) Identification of novel sphingolipid-binding motifs in mammalian membrane proteins. Biochim Biophys Acta 1838:2066-2070

Contreras FX, Ernst AM, Haberkant P, Björkholm P, Lindahl E, Gönen B, Tischer C, Elofsson A, von Heijne G, Thiele C, Pepperkok R, Wieland F, Brügger B (2012) Molecular recognition of a single sphingolipid species by a protein's transmembrane domain. Nature 481:525-529

Das N, Dai J, Hung I, Rajagopalan MR, Zhou HX, Cross TA (2015) Structure of CrgA, a cell division structural and regulatory protein from Mycobacterium tuberculosis, in lipid bilayers. Proc Natl Acad Sci USA 112:E119-E126

Davis JH, Jeffrey KR, Bloom M, Valic MI, Higgs TP (1976) Quadrupolar echo deuteron magnetic resonance spectroscopy in ordered hydrocarbon chains. Chem Phys Lett 42:390-394

Derganc J, Antonny B, Copic A (2013) Membrane bending: the power of protein imbalance. Trends Biochem Sci 38:576-584

Diaz-Horta O, Cintado A, Fernandez-De-Cossio ME, Nazabal M, Ferrer A, Roca J, Camacho H, Benitez J, Ale M, Villarreal A, Molina G, Vera M, Cabrera-Rode E, Novoa L (2010) Relationship of type 1 diabetes to ancestral proportions and HLA DR/ DQ alleles in a sample of the admixed Cuban population. Ann Hum Biol 37:778-788

Dixon AM, Roy S (2019) Role of membrane environment and membrane-spanning protein regions in assembly and function of the class II major histocompatibility complex. Hum Immunol 80:5-14

Dixon AM, Drake L, Hughes KT, Sargent E, Hunt D, Harton JA, Drake JR (2014) Differential transmembrane domain GXXXG motif pairing impacts major histocompatibility complex (MHC) class II structure. J Biol Chem 289:11695-11703

Drake LA, Drake JR (2016) A triad of molecular regions contribute to the formation of two distinct MHC class II conformers. Mol Immunol 74:59-70

Dufourc EJ (2008) Sterols and membrane dynamics. J Chem Biol 1:63-77

Fung BM, Khitrin AK, Ermolaev K (2000) An improved broadband decoupling sequence for liquid crystals and solids. J Magn Reson 142:97-101

Gambelunghe G, Brozzetti A, Ghaderi M, Candeloro P, Tortoioli C, Falorni A (2007) MICA gene polymorphism in the pathogenesis of type 1 diabetes. Ann NY Acad Sci 1110:92-98

Gopinath T, Mote KR, Veglia G (2015) Simultaneous acquisition of 2D and 3D solid-state NMR experiments for sequential assignment of oriented membrane protein samples. J Biomol NMR 62:53-61

Grage SL, Afonin S, Kara S, Buth G, Ulrich AS (2016) Membrane thinning and thickening induced by membrane-active amphipathic peptides. Front Cell Dev Biol 4:65

Hallock KJ, Lee DK, Ramamoorthy A (2003) MSI-78, an analogue of the magainin antimicrobial peptides, disrupts lipid bilayer structure via positive curvature strain. Biophys J 84:3052-3060

\begin{tabular}{|l|l|l|l|l|}
\hline Journal : Large 232 & Article No: 71 & Pages : 14 & MS Code : 71 & Dispatch : 31-5-2019 \\
\hline
\end{tabular}


Harmouche N, Bechinger B (2018) Lipid-mediated interactions between the amphipathic antimicrobial peptides magainin 2 and PGLa in phospholipid bilayers. Biophys J 115:1033-1044

Harzer U (2000) Untersuchungen zur topologie und struktur von membranproteinen. $\mathrm{PhD}$, Technical University. Munich

Hille B, Dickson EJ, Kruse M, Vivas O, Suh BC (2015) Phosphoinositides regulate ion channels. Biochim Biophys Acta 1851:844-856

Holt A, Rougier L, Reat V, Jolibois F, Saurel O, Czaplicki J, Killian JA, Milon A (2010) Order parameters of a transmembrane helix in a fluid bilayer: case study of a WALP peptide. Biophys J 98:1864-1872

Hong M (2006) Oligomeric structure, dynamics, and orientation of membrane proteins from solid-state NMR. Structure 14:1731-1740

Huang HW (2000) Action of antimicrobial peptides: two-state model. Biochemistry 39:8347-8352

Itkin A, Salnikov ES, Aisenbrey C, Raya J, Raussens V, Ruysschaert JM, Bechinger B (2017) Evidence for heterogeneous conformations of the gamma cleavage site within the amyloid precursor proteins transmembrane domain ACS. Omega 2:6525-6534

Jenne N, Frey K, Brugger B, Wieland FT (2002) Oligomeric state and stoichiometry of p24 proteins in the early secretory pathway. J Biol Chem 277:46504-46511

Kemayo Koumkoua P, Aisenbrey C, Salnikov ES, Rifi O, Bechinger B (2014) On the design of supramolecular assemblies made of peptides and lipid bilayers. J. Peptide Sci. 20:526-536

Kim C, Spano J, Park EK, Wi S (2009) Evidence of pores and thinned lipid bilayers induced in oriented lipid membranes interacting with the antimicrobial peptides, magainin-2 and aurein-3.3. Biochim Biophys Acta 1788:1482-1496

King G, Dixon AM (2010) Evidence for role of transmembrane helixhelix interactions in the assembly of the class II major histocompatibility complex. Mol BioSyst 6:1650-1661

Langer JD, Roth CM, Bethune J, Stoops EH, Brugger B, Herten DP, Wieland FT (2008) A conformational change in the alpha-subunit of coatomer induced by ligand binding to gamma-COP revealed by single-pair FRET. Traffic 9:597-607

Loudet C, Khemtemourian L, Aussenac F, Gineste S, Achard MF, Dufourc EJ (2005) Bicelle membranes and their use for hydrophobic peptide studies by circular dichroism and solid state NMR. Biochem Biophys Acta 1724:315-323

Marquette A, Bechinger B (2018) Biophysical investigations elucidating the mechanisms of action of antimicrobial peptides and their synergism. Biomolecules 8:E18

Michalek M, Salnikov E, Werten S, Bechinger B (2013) Structure and topology of the huntingtin 1-17 membrane anchor by a combined solution and solid-state NMR approach. Biophys J 105:699-710

Nagle JF, Tristram-Nagle S (2000) Structure of lipid bilayers. Biochim Biophys Acta 1469:159-195

Painter CA, Stern LJ (2012) Conformational variation in structures of classical and non-classical MHCII proteins and functional implications. Immunol Rev 250:144-157

Palsdottir H, Lojero CG, Trumpower BL, Hunte C (2003) Structure of the yeast cytochrome bc1 complex with a hydroxyquinone anion Qo site inhibitor bound. J Biol Chem 278:31303-31311

Perrone B, Miles AJ, Salnikov ES, Wallace B, Bechinger B (2014) Lipid-interactions of the LAH4, a peptide with antimicrobial and nucleic transfection activities Eur. Biophys J 43:499-507

Ramamoorthy A, Lee DK, Narasimhaswamy T, Nanga RPR (2010) Cholesterol reduces pardaxin's dynamics-a barrel-stave mechanism of membrane disruption investigated by solid-state NMR. Biochim Biophys Acta 1798:223-227

Rance M, Byrd RA (1983) Obtaining high-fidelity spin-1/2 powder spectra in anisotropic media: phase-cycled Hahn echo spectroscopy. J Magn Reson 52:221-240
Raya J, Perrone B, Bechinger B, Hirschinger J (2011) Chemical shift powder spectra obtained by using rotor-directed exchange of orientations cross-polarization (RODEO-CP). Chem Phys Lett 508:155-164

Reinhard C, Harter C, Bremser M, Brugger B, Sohn K, Helms JB, Wieland F (1999) Receptor-induced polymerization of coatomer. Proc Natl Acad Sci USA 96:1224-1228

Resende JM, Verly RM, Aisenbrey C, Amary C, Bertani P, Pilo-Veloso D, Bechinger B (2014) Membrane interactions of phylloseptin-1, -2 , and -3 peptides by oriented solid-state NMR spectroscopy. Biophys J 107:901-911

Russ WP, Engelman DM (2000) The GxxxG motif: a framework for transmembrane helix-helix association. J Mol Biol 296:911-919

Salnikov E, Bertani P, Raap J, Bechinger B (2009a) Analysis of the amide (15)N chemical shift tensor of the C(alpha) tetrasubstituted constituent of membrane-active peptaibols, the alpha-aminoisobutyric acid residue, compared to those of di- and tri-substituted proteinogenic amino acid residues. J Biomol NMR 45:373-387

Salnikov ES, Mason AJ, Bechinger B (2009b) Membrane order perturbation in the presence of antimicrobial peptides by $2 \mathrm{H}$ solid-state NMR spectroscopy. Biochimie 91:743

Salnikov ES, Mason AJ, Bechinger B (2009c) Membrane order perturbation in the presence of antimicrobial peptides by $2 \mathrm{H}$ solid-state NMR spectroscopy. Biochimie 91:734-743

Salnikov E, Aisenbrey C, Vidovic V, Bechinger B (2010) Solid-state NMR approaches to measure topological equilibria and dynamics of membrane polypeptides. Biochim Biophys Acta 1798:258-265

Salnikov E, Aisenbrey C, Balandin SV, Zhmak MN, Ovchinnikova AY, Bechinger B (2011) Structure and alignment of the membraneassociated antimicrobial peptide arenicin by oriented solid-state NMR spectroscopy. Biochemistry 50:3784-3795

Salnikov ES, Aisenbrey C, Anantharamaiah GM, Bechinger B (2019) Solid-state NMR structural investigations of peptide-based nanodiscs and of transmembrane helices in bicellar disc arrangements. Chem Phys Lipid 219:58-71

Sato T, Tang TC, Reubins G, Fei JZ, Fujimoto T, Kienlen-Campard P, Constantinescu SN, Octave JN, Aimoto S, Smith SO (2009) A helix-to-coil transition at the epsilon-cut site in the transmembrane dimer of the amyloid precursor protein is required for proteolysis. Proc Natl Acad Sci USA 106:1421-1426

Smith SO, Eilers M, Song D, Crocker E, Ying W, Groesbeek M, Metz G, Ziliox M, Aimoto S (2002) Implications of threonine hydrogen bonding in the glycophorin A transmembrane helix dimer. Biophys J 82:2476-2486

Stangl M, Schneider D (2015) Functional competition within a membrane: lipid recognition vs. transmembrane helix oligomerization. Biochim Biophys Acta 1848:1886-1896

Strating JR, Martens GJ (2009) The p24 family and selective transport processes at the ER-Golgi interface. Biol Cell 101:495-509

Travers P, Blundell TL, Sternberg MJE, Bodmer WF (1984) Structural and evolutionary analysis of HLA-D-region products. Nature 310:235-238

Tsai S, Santamaria P (2013) MHC class II polymorphisms, autoreactive T-cells, and autoimmunity. Front Immunol 4:321

Vogt TCB, Ducarme P, Schinzel S, Brasseur R, Bechinger B (2000) The topology of lysine-containing amphipathic peptides in bilayers by CD, solid-state NMR and molecular modelling. Biophys J 79:2644-2656

Publisher's Note Springer Nature remains neutral with regard to jurisdictional claims in published maps and institutional affiliations. 


\section{Journal: 232}

Article: $\quad \mathbf{7 1}$

\section{Author Query Form}

\section{Please ensure you fill out your response to the queries raised below and return this form along with your corrections}

Dear Author

During the process of typesetting your article, the following queries have arisen. Please check your typeset proof carefully against the queries listed below and mark the necessary changes either directly on the proof/online grid or in the 'Author's response' area provided below

\begin{tabular}{|l|l|l|}
\hline Query & Details Required & Author's Response \\
\hline AQ1 & $\begin{array}{l}\text { Please check and confirm that the authors and their respective affiliations have been } \\
\text { correctly identified and amend if necessary. }\end{array}$ & \\
\hline AQ2 & Kindly check and confirm the edit made in the article title. & \\
\hline AQ3 & Please restrict the keywords to 3-6. & \\
\hline AQ4 & $\begin{array}{l}\text { Please check the clarity of the sentence 'Furthermore, whereas previous studies } \\
\text { have...' and amend if necessary. }\end{array}$ & \\
\hline AQ5 & Please check the clarity of the sentence 'Interestingly at...' and amend if necessary. & \\
\hline AQ6 & $\begin{array}{l}\text { As per the information provided by the publisher, Figs. 1 and 4 will be black and } \\
\text { white in print; hence, please confirm whether we can add "colour figure online" to the } \\
\text { caption. }\end{array}$ & \\
\hline
\end{tabular}

